\title{
Anthropometry of Internal Acoustic Meatus
}

\author{
Antropometría del Meato Acústico Interno
}

"Reza Masteri Farahani; ${ }^{* *}$ Mehrdad Nooranipour \& **Kamran Vafaei Nikakhtar

FARAHANI, R. M.; NOORANIPOUR, M. \& NIKAKHTAR, K. V. Anthropometry of internal acoustic meatus. Int. J. Morphol., 25(4):861-865, 2007.

SUMMARY: Knowledge of the normal dimensions and local anatomy of the internal acoustic canal (IAM) is necessary during evaluation of temporal bone trauma, congenital anomalies, affecting the individual nerves, and some neuro-otologic surgeries. The purpose of this study was therefore to characterize the anthropometry of the IAM. We made the following measurements in 14 normal temporal bones of Iranian male skulls from individuals 35 to 60 years of age (average of 50): Height and width of the middle portion of the IAM (mean 4.04 and $3.69 \mathrm{~mm}$ ), Height and width of the fundus of the IAM (mean 2.86 and $2.43 \mathrm{~mm}$ ), inferior and superior length of the IAM (mean 8.39 and $10.75 \mathrm{~mm}$ ). This study provides baseline information that maybe used to evaluate the congenital anomalies of the IAM. These data may also be helpful in the presurgical evaluations of the patients undergoing surgeries involving the IAM.

KEY WORDS: Internal acoustic meatus; Anthropometry; Anatomy; Temporal Bone.

\section{INTRODUCTION}

The internal acoustic meatus (IAM) is a short bony canal that lies between the posterior surface of the petrous pyramid and the bony labyrinth within the dense petrous bone (Standring, 2005); the IAM opens medially to the posterior canal fossa through the porus acusticus. The seventh and eighth cranial nerves pass through the IAM, and this canal has been clinically important as a region in which acoustic neuromas occur. Many investigators have studied the IAM on radiographs, on casts, in dissected temporal bones, and in histologic sections (Amjad et al., 1969; Schuknecht \& Gulja, 1986; Silverstein et al., 1988; Fujita \& Sando, 1994; Bosbuga et al., 1998; Lescanne et al., 2002), and have found that the dimensions, shape, and volume of the normal adult IAM vary widely, even between to sides of the same individual, as well as among different individuals.

After studying postnatal development of the IAM, Lang reported the lengths and the vertical and horizontal diameters in four age groups from newborn to adult. Similar studies by Papangelou (1975) found no growth with age in the wall lengths, the diameter, or the volume of the IAM in individuals older than 10 years. Sakashita \& Sandu (1995) studied postnatal developmental of the IAM by computeraided $3 \mathrm{D}$ reconstruction and measurement. We did this study to characterize the anthropometry of IAM to provide baseline information that may be helpful in head and neck surgery.

\section{MATERIAL AND METHOD}

Fourteen human temporal bones obtained from Iranian cadavers without a history congenital anomaly or otologic diseases, in 2005, were studied. Specimens consisted of five pairs of temporal bones from five human skulls ( 5 right and 5 left temporal bones), three left temporal bones, and one right temporal bone. The individuals average of age was 50 years old (35 to 60), and the sexual dimorphism landmarks indicated that all were male. Using callipers we made the following 9 measurements with an accuracy of 0.1 $\mathrm{mm}$ :

- Height of the middle portion of IAM: vertical diameter of IAM at the middle portion of the meatus.

- Width of the middle portion of IAM: horizontal diameter of IAM at the middle portion of the meatus.

- Inferior length of IAM: the distance from the inferior margin of the porus to the most lateral point of the fundus in the lamina cribrosa area for the inferior vestibular nerve.

- Superior length of IAM: the distance from the superior margin of the porus to the most lateral point of the fundus

* PhD. Department of Anatomy of Shahid Beheshti University of Medical Sciences and Health Services, Tehran, Iran.

** MD. Faculty of Medicine, Shahid Beheshti University of Medical Sciences and Health Services, Tehran, Iran. 
in the lamina cribrosa area for the superior vestibular nerve. - Length of the posterior surface of the petrous: the length of the straight line drawn from the apex to the base of the posterior surface of the petrous which divides the porus to superior and inferior parts.

- Height of the fundus of IAM: vertical diameter of IAM at the fundus.

- Width of the fundus of IAM: horizontal diameter of IAM at the fundus.

- Width of porus: horizontal diameter of IAM at the porus.

- Height of porus: vertical diameter of IAM at the porus.

For making the cast of the IAM different materials were used including dental alginate, wax, paraffin, cellophane covered mud, silk paper pulp and several other materials. The best cast was made by silk paper pulp because it did not have any adhesion within the canal, coming out completely in its original form. All the measurements were done by the same person. The data was analyzed by SPSS 11 software and the attained data was extracted in statistical tables.

\section{RESULTS}

Middle portion of IAM. Height and width of the middle portion of IAM ranged between 3 and $5 \mathrm{~mm}$ (mean \pm SD, $4.04 \pm 0.639 \mathrm{~mm})$, and 3 and $5 \mathrm{~mm}(3.96 \pm$ $0.692 \mathrm{~mm})$, respectively.

Length. The inferior and superior length of IAM ranged between 7 and $11 \mathrm{~mm}(8.39 \pm 1.119 \mathrm{~mm})$, and 8 and $14 \mathrm{~mm}(10.75 \pm 1.655 \mathrm{~mm})$, respectively. The average length of the posterior surface of petrous was $53.39 \pm 4.567 \mathrm{~mm}$ (range 45-60mm).

Fundus. The height and width of the fundus of IAM ranged between 2.5 and $4 \mathrm{~mm}(2.86 \pm 0.397 \mathrm{~mm})$, and 2 and $3 \mathrm{~mm}(2.43 \pm 0.416 \mathrm{~mm}$, ) respectively.

Porus. The width and height of the porus ranged between 3 and $7 \mathrm{~mm}(5.04 \pm 1.048)$, and 3 and $6 \mathrm{~mm}$ $(4.11 \pm 0.631 \mathrm{~mm})$, respectively.

Table I. Demonstrates the above measurement.

\begin{tabular}{c|ccccccccc}
\hline No. & A & B & C & D & E & F & G & H & I \\
\hline $1 \mathrm{~L}$ & 3 & 3 & 11 & 10 & 58 & 2.5 & 2.5 & 6 & 4 \\
$2 \mathrm{R}$ & 3.5 & 3 & 8 & 11 & 59 & 2.5 & 2 & 5 & 3 \\
$3 \mathrm{~L}$ & 4 & 4 & 9 & 9 & 52 & 3 & 3 & 4 & 4 \\
$4 \mathrm{R}$ & 5 & 3 & 7.5 & 11 & 50 & 2.5 & 3 & 5 & 4.5 \\
$5 \mathrm{~L}$ & 4 & 5 & 7 & 9 & 55 & 2.5 & 2 & 3 & 4.5 \\
$6 \mathrm{R}$ & 4 & 4 & 7 & 10.5 & 55.5 & 3 & 2.5 & 4.5 & 4 \\
$7 \mathrm{~L}$ & 3 & 4 & 9 & 13 & 52 & 3 & 2.5 & 4 & 4 \\
$8 \mathrm{R}$ & 4 & 3.5 & 8 & 10 & 58 & 3 & 2.5 & 5 & 4 \\
$9 \mathrm{~L}$ & 5 & 4.5 & 9.5 & 12 & 60 & 3 & 3 & 7 & 6 \\
$10 \mathrm{R}$ & 5 & 5 & 7 & 9 & 55 & 4 & 3 & 7 & 4 \\
$11 \mathrm{~L}$ & 4 & 4 & 9 & 14 & 54 & 2.5 & 2 & 5 & 4 \\
$12 \mathrm{~L}$ & 4.5 & 5 & 9 & 12 & 47 & 3 & 2 & 5 & 4 \\
$13 \mathrm{~L}$ & 4 & 3.5 & 9 & 12 & 45 & 2.5 & 2 & 5 & 4 \\
$14 \mathrm{R}$ & 3.5 & 4 & 7.5 & 8 & 47 & 3 & 2 & 5 & 3.5 \\
\hline Mean & 4.04 & 3.96 & 8.39 & 10.75 & 53.39 & 2.86 & 2.43 & 5.04 & 4.11 \\
Range & $3-5$ & $3-5$ & $7-11$ & $8-14$ & $45-60$ & $2.5-4$ & $2-3$ & $3-7$ & $3-6$ \\
SD & 0.639 & 0.692 & 1.119 & 1.655 & 4.567 & 0.397 & 0.416 & 1.048 & 0.631 \\
$\%$ SD & $15.81 \%$ & $17.47 \%$ & $13.33 \%$ & $15.39 \%$ & $8.55 \%$ & $13.88 \%$ & $17.11 \%$ & $20.79 \%$ & $15.35 \%$ \\
\hline
\end{tabular}

The measures are presented in millimeters. A) Height of the middle portion of IAM. BWidth of the middle portion of IAM. C) Inferior length of IAM. D) Superior length of IAM. E) Length of the posterior surface of the petrous. F) Height of the fundus of IAM. ONidth of the fundus of IAM. HWidth of porus. I) Height of porus. SD: Standard Deviation. L: LeftTemporal bone. R: RightTemporal bone. 
FARAHANI, R. M.; NOORANIPOUR, M. \& NIKAKHTAR, K. V. Anthropometry of internal acoustic meatus. Int. J. Morphol., 25(4):861-865, 2007.

Table II. Some indices were also calculated in order to make a 3D evaluation of the structure.

\begin{tabular}{c|ccccc}
\hline No. & $\mathrm{B} / \mathrm{A}$ & $\mathrm{G} / \mathrm{F}$ & $\mathrm{C} / \mathrm{E}$ & $\mathrm{D} / \mathrm{E}$ & $\mathrm{H} / \mathrm{I}$ \\
\hline 1L & 1.00 & 1.00 & 0.19 & 0.17 & 1.50 \\
2R & 0.86 & 0.80 & 0.14 & 0.19 & 1.67 \\
3L & 1.00 & 1.00 & 0.17 & 0.17 & 1.00 \\
4R & 0.60 & 1.20 & 0.15 & 0.22 & 1.11 \\
5L & 1.25 & 0.80 & 0.13 & 0.16 & 0.67 \\
6R & 1.00 & 0.83 & 0.13 & 0.19 & 1.13 \\
7L & 1.33 & 0.83 & 0.17 & 0.25 & 1.00 \\
8R & 0.88 & 0.83 & 0.14 & 0.17 & 1.25 \\
9L & 0.90 & 1.00 & 0.16 & 0.16 & 1.17 \\
10R & 1.00 & 0.75 & 0.13 & 0.26 & 1.75 \\
11L & 1.00 & 0.80 & 0.17 & 0.26 & 1.25 \\
12L & 1.11 & 0.67 & 0.19 & 0.27 & 1.25 \\
13L & 0.88 & 0.80 & 0.20 & 0.17 & 1.25 \\
14R & 1.14 & 0.67 & 0.16 & 0.20 & 1.43 \\
\hline Mean & 1.00 & 0.86 & 0.16 & $0.16-0.27$ & 1.24 \\
Range & $0.60-1.33$ & $0.67-1.20$ & $0.13-0.20$ & 0.0396 & $0.67-1.75$ \\
SD & 0.1735 & 0.1403 & $16.31 \%$ & $14.25 \%$ & 0.3248 \\
\%SD & $17.35 \%$ & & & $26.19 \%$
\end{tabular}

A) Height of the middle portion of IAM. B) Width of the middle portion of IAM. C) Inferior length of IAM. D) Superior length of IAM. E) Length of the posterior surface of the petrous. F) Height of the fundus of IAM. G) Width of the fundus of IAM. H) Width of porus. I) Height of porus. SD: Standard Deviation. L: Left Temporal bone. R: Right Temporal bone.

\section{DISCUSSION}

The structure and anthropometry of internal acoustic meatus has been studied sporadically. Moeller (2000) in his book "Normal findings in radiology" reckoned the width and length of IAM 5mm (2-12mm) and $8 \mathrm{~mm}(4-25 \mathrm{~mm})$, respectively. Sakashita \& Sando in their paper in 1995 described the anthropometry of IAM in addition to its $3 \mathrm{D}$ structure. They found the height and width of the middle portion of IAM $4.8 \mathrm{~mm}(3.2-6.5 \mathrm{~mm})$ and $4.9 \mathrm{~mm}(3.1-7 \mathrm{~mm})$, the height and width of the fundus of IAM $4.5 \mathrm{~mm}$ (3.7$5.6 \mathrm{~mm})$ and $4.6 \mathrm{~mm}(3.3-5.7 \mathrm{~mm})$, and inferior length of IAM $9.6 \mathrm{~mm}(14.5-13.7 \mathrm{~mm})$ in comparison to our study, which figures variations in sizes which may be due to differences in race and sex.

Furthermore, they measured superior length of IAM $10.6 \mathrm{~mm}(6.9-14.1 \mathrm{~mm})$, which is very close to our measurement.

According to our study, the superior and inferior length of IAM were about one fifth and one sixth of the length of petrous bone, respectively. Moreover, within the fundus of IAM width of the meatus was less than its height while in the middle portion of IAM they were almost the same. Width of porus was $24 \%$ more than its height, it resembles an irregular oval.

\section{CONCLUSION}

Our 14 samples were all from the same gender and geographic area. This limits the spectrum of differences, but it provides a more homogenous approach to measurement. Some of them are different from and some were close to previous studies.

This study provides baseline information that maybe used to evaluate the congenital anomalies of the IAC. These data may also be helpful in the presurgical evaluations of the patients undergoing surgeries involving the IAC. 

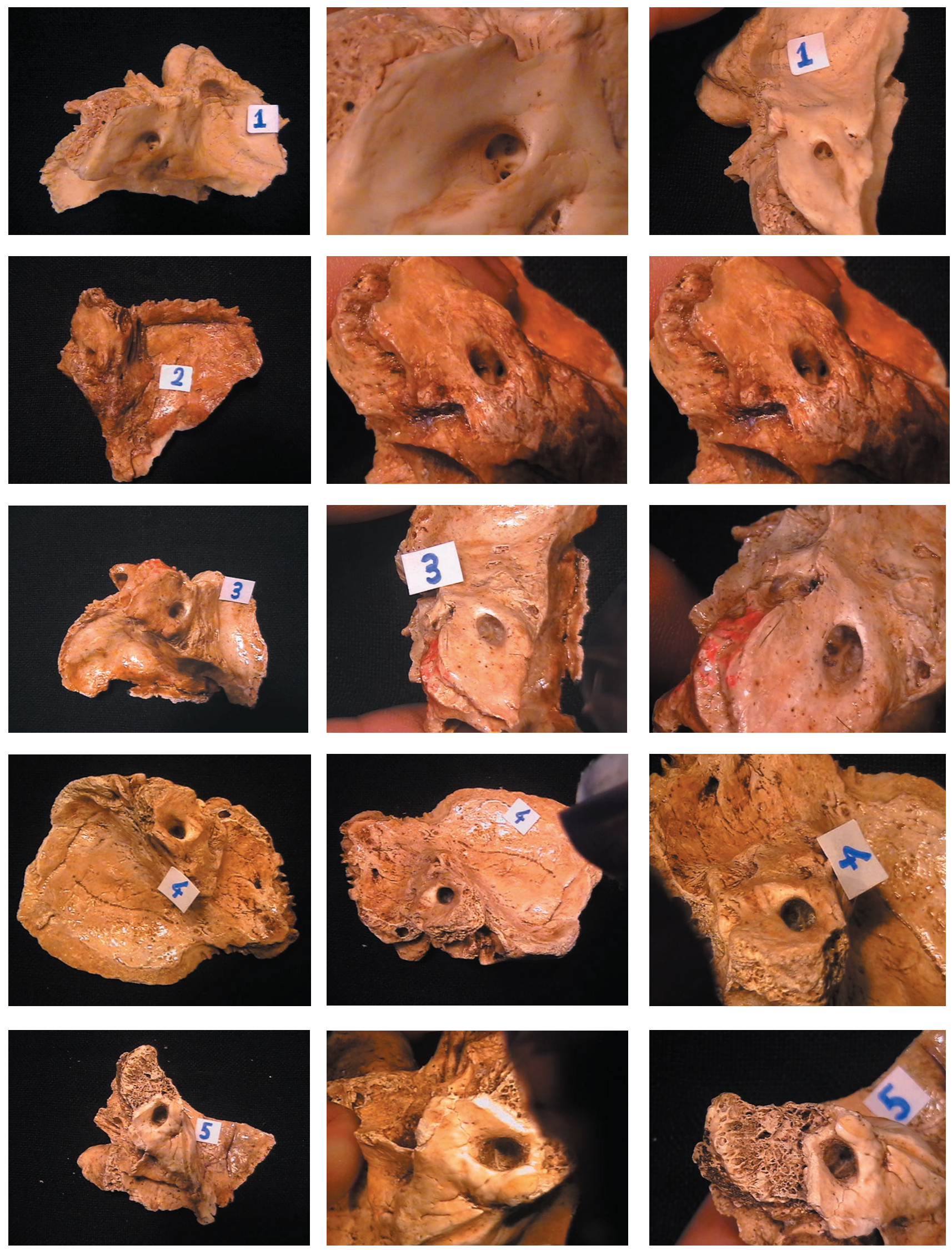
FARAHANI, R. M.; NOORANIPOUR, M. \& NIKAKHTAR, K. V. Antropometría del meato acústico interno. Int. J. Morphol., 25(4):861-865, 2007.

RESUMEN: El conocimiento de las dimensiones normales y de la anatomía local del meato acústico interno (MAI) es necesario durante la evaluación del trauma del hueso temporal, anomalías congénitas que afectan a nervios individuales y algunas cirugías neurootológicas. El objetivo del trabajo fue caracterizar la antropometría del MAI. Las siguientes mediciones las realizamos en 14 huesos temporales normales de individuos iraníes masculinos, de 35 a 60 años de edad (promedio 50 años): altura y ancho de la porción media del MAI (4,04 y 3,69mm), altura y ancho del fondo del MAI (2,86 y 2,43mm), largo inferior y largo superior del MAI (promedio 8,39 y $10,75 \mathrm{~mm}$ ). Este estudio entrega información básica que puede ser usada para evaluar anomalías congénitas del MAI. Estos datos también pueden ayudar en evaluaciones prequirúrgicas de pacientes que serán sometidos a cirugías que involucren el MAI.

PALABRAS CLAVE: Meato acústico interno; Antropometría; Anatomía; Hueso temporal.

\section{REFERENCES}

Amjad, A. H.; Scheer, A. A. \& Rosenthal, J. Human internal auditory canal. Arch. Otolaryngol., 89(5):709, 1969.

Bozbuga, M.; Ozturk, A.; Ari, Z.; Sahinoglu, K.; Bayraktar, B.; Polat, G. \& Gruel, I. Surgical anatomy of the temporal bone and measurements of the skull base for transpetrosal approaches. Okajimas Folia Anat. Jpn., 75:33-9, 1998.

Fujita, S. \& Sando, I. Postnatal development of the vestibular aqueduct in relation to the internal auditory canal. Computer-aided three-dimensional reconstruction and measurement study. Ann. Otol. Rhinol. Laryngol., 103:719-22, 1994.

Lescanne, E.; Evelut, S.; Lefrancq, T. \& Destrieux, Ch. The internal acoustic meatus and its meningeal layers: a microanatomical study. Neurosurgery, 97(5), 2002.

Moeller, T. B. Normal findings in radiology. Thieme, 2000, p. 33 .

Papangelou, L. Study of the human internal auditory canal in relation to age and sex. J. Laryngol. Otol., 89:79-89, 1975.

Sakashita, T. \& Sando, I. Postnatal development of internal auditor canal studied by computer aided three dimensional reconstruction and measurements. Ann. Otol. Rhinol.Laryngol., 104(6):469-75, 1995.

Schuknecht, H. F. \& Gulya, A. J. Anatomy of the temporal bone with surgical implications. Philadelphia, Lea \& Febiger, 1986. pp. 305-32.

Silverstein, H.; Norrell, H.; Smouha, E. \& Haberkamp, T. The singular canal: a valuable landmark in surgery of the internal auditory canal. Otolaryngol. Head Neck Surg., 98:138-43, 1988.

Standring, S. Gray's Anatomy: The anatomical bases of clinical practice. $39^{\text {th }}$ Ed. Elsevier, Churchill, Livingstone, 2005. pp. 463, 468-71.

\section{Correspondencia:}

Dr. Mehrdad Nooranipour

Faculty of Medicine

Shahid Beheshti University

of Medical Sciences and Health Services

Tehran, IRAN

Email: amoojim@yahoo.com

Received: 05-04-2007

Accepted: 11-09-2007 
